\title{
Common Ingredients and Orographic Rain Index (ORI) for Heavy Precipitation Associated with Tropical Cyclones Passing Over the Appalachian Mountains
}

\author{
Riem Rostom ${ }^{1} \&$ Yuh-Lang Lin $^{2}$ \\ ${ }^{1}$ Department of Applied Engineering \& Technology, Indiana State University, Terre Haute, Indiana, USA \\ ${ }^{2}$ Department of Physics and Applied Science \& Technology PhD Program, North Carolina A\&T State University, \\ Greensboro, North Carolina, USA
}

Correspondence: Yuh-Lang Lin, 302H Gibbs Hall, AST PhD Program, North Carolina A\&T State University, Greensboro, NC, 27411, USA. E-mail: ylin@ ncat.edu

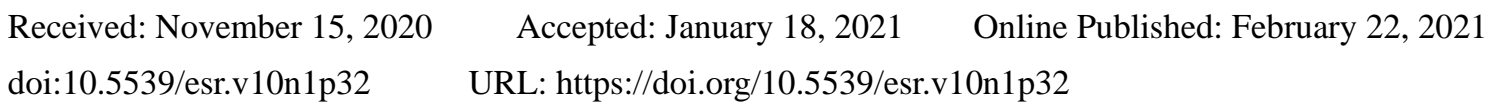

\begin{abstract}
Relative contributions of common ingredients to heavy orographic rainfall associated with the passage of Hurricanes Hugo (1989) and Isabel (2003) over the Appalachian Mountains are examined using a numerical weather prediction model. It is found that the key ingredients for producing local heavy orographic rainfall were: high precipitation efficiency, strong low-level flow, strong orographically forced upward motion associated with strong low-level flow over relatively gentle upslope, concave geometry providing local areas of convergence, high moist flow upstream, a relatively large convective system associated with both tropical cyclones (TCs), and relatively slower movement. In addition, neither conditional instability nor potential (convective) instability is found to play essential roles in producing strong upward motion leading to heavy orographic TC rain. A modified Orographic Rain Index (ORI) is proposed as a predictor for heavy orographic TC precipitation, which includes the upstream incoming horizontal wind speed normal to the local orography, the steepness of the mountain, the relative humidity, the TC moving speed, and the horizontal scale of the TC. It is found that the ORI estimated in regions of local maximum rainfall by using fine-resolution numerically simulated results correlate well with rainfall rates for both hurricanes, indicating that it may serve as a predictor for heavy orographic TC rainfall.
\end{abstract}

Keywords: orographic rain, hurricane, tropical cyclone (TC), common ingredients, orographic rain index (ORI)

\section{Introduction}

When a tropical cyclone (TC) passes over a mesoscale mountain, its cyclonic circulation may generate strong upward motion when it impinges on a mesoscale mountain, which tends to initiate or enhance heavy rainfall leading to flash flooding and debris flow. These flash flood and/or debris flow may cause fatality, property damage, and economic loss, such as those occurred when Hurricanes Camille (1969), Hugo (1989), Isabel (2003), and Ivan (2004) (e.g., Stewart 2005, Schwarz 1970, Hollifield and Lackey 1989, Roth 2005) among others, approached or passed over the southern and central Appalachian Mountains.

The preexisting moist convection embedded in rainbands and eyewall of a TC tends to be enhanced by mountains and to produce heavy orographic rainfall (e.g., Smith 1979; Lin 2007; Houze 2012). The dynamics of orographic rain initiation and/or enhancement through mechanical (lifting/blocking) and thermal forcing is still not well understood, which requires further investigation. In particular, when the precipitation events are accompanied by a preexisting weather system, such as a TC. The strong and very moist low-level flow associated with strong TC vortex circulation provided at least two (i.e., strong low-level flow and high moisture) key common ingredients for producing heavy orographic rainfall, as proposed in Lin et al. (2001), which help induce and/enhance rainfall on the upslope of mountains during the passage of a TC (e.g., Wu et al. 2002, Witcraft et al. 2005, Huang and Lin 2014). In addition to these two common ingredients for heavy orographic rainfall, relative contributions from other common ingredients associated with TCs remain unclear, which deserve further investigation.

For a two-dimensional mountain range, the precipitation is proportional to the moisture flux convergence accompanying orographic rain, which can be estimated if we assume that moisture convergence is mainly contributed from horizontal wind hitting upon the mountain slope (Alpert 1986). Based on Alpert's approach and Doswell et al.'s (1996) ingredient 
approach, Lin et al. (2001; denoted as Lin01) and Lin (2007) proposed that the upslope orographic precipitation can be estimated by the following:

$$
P=\varepsilon\left(\frac{\rho_{a}}{\rho_{w}}\right)\left(\boldsymbol{V}_{H} \cdot \nabla h+w_{e n v}\right) q_{v}\left(\frac{L_{s}}{c_{s}}\right),
$$

where $\varepsilon$ is the precipitation efficiency, $\rho_{a}$ the air density, $\rho_{w}$ the liquid water density, $\boldsymbol{V}_{H}$ the low-level horizontal wind velocity, $h$ the mountain height function, $w_{e n v}$ the environmentally-forced upward motion, $q_{v}$ the lower-layer water vapor mixing ratio, and $L_{s}$ and $c_{s}$ the horizontal scale and moving speed of the convective system in the direction of the system's movement. Note that in Eq. (1), the upslope vertical motion is decomposed into orographically and environmentally induced upward motion. The orographically forced upward motion $\left(\boldsymbol{V}_{H} \cdot \nabla h\right)$ may be approximately estimated by the free-slip lower boundary condition for flow over the local terrain and the environmentally forced upward motion $\left(w_{e n v}\right)$ can be estimated by synoptic flow, such as conditional instability, potential (convective) instability, low-level convergence, and upper-level divergence. In the present approach, we require both the orographically and environmentally forced vertical motion to be positive. The former implies that this ingredient approach only applies to upslope orographic rain.

Note that the major differences of the current approach from Doswell et al. (1996) are that: (a) the vertical motion is decomposed linearly to orographically forced and environmentally forced, while in Doswell et al.'s approach there is no distinction of these two types of vertical motion, (b) the orographically forced vertical motion is explicitly represented by the lower-boundary condition approximately, (c) the vertical moisture flux in Dowsell et al., $w q$, is replaced by the vertical water vapor flux, $w q_{v}$, thus the condensation of water vapor into water is taken into account by the conversion factor, $\rho_{a} / \rho_{w}$.

Based on the above common ingredient approach, Lin01 proposed a two-dimensional Orographic Rain Index (ORI), $U(d h / d x) q_{v}$, similar to that of Alpert (1986) except with the precipitation efficiency, precipitation duration, and conversion factor $\left(\rho_{d} / \rho_{w}\right)$ from the condensation of water vapor to water were taken into consideration, and tested with several heavy orographic rain events. The results were compared reasonably well with observations. When a TC approaches a mesoscale mountain, the moist flow regime and orographic rain enhancement mechanisms may behave quite differently from those associated with midlatitude precipitating systems or non-TC precipitating systems in tropics. For example, Huang and Lin (2014) found that the huge amount of rain associated with Typhoon Morakot (2009) during its passage over the Central Mountain Range (CMR) of Taiwan was mainly produced by typhoon's slow movement, strong orographic lifting, and the confluence between the typhoon's outer circulation and the southwesterly monsoonal current, instead of due to large convective available potential energy (CAPE), unlike that found in Supertyphoon Bilis (2000) over CMR (Witcraft et al. 2005). This result is consistent with several parallel studies (e.g., Lin et al. 2002, Chiao and Lin 2003, Hong et al. 2010, C.-Y. Lin et al. 2011, Wu et al. 2011, Chien and Kuo 2011, Yen et al. 2011). In order to examine the relative contributions of the common ingredients of the proposed ORI associated with the orographic TC rain, we select two hurricanes, Hugo (1989) and Isabel (2003), due to their similarity in impinging angle on the Appalachian Mountains and very different orographic rainfall. This allows us to isolate the study to better determine the common ingredients that caused heavy orographic rainfall.

The rest of the paper is organized as follows. Section 2 describes the selection and synopsis of Hugo (1998) and Isabel (2003) for examining the key ingredients for heavy orographic rain. Section 3 provides a description of the Weather Research and Forecasting (WRF) model (Skamarock et al. 2008) and the experimental design for this study. Section 4 discusses the estimation of the flow and orographic parameters based on the numerically-simulated results for examining the key ingredients and proposes a modified ORI for heavy precipitation in Sec. 5. Section 6 provides the summary and concluding remarks.

\section{Selection and Synopses of Two Tropical Cyclones Passing Over the Appalachians, Hugo (1989) and Isabel (2003)}

Based on the National Hurricane Center's (NHC's) six-hourly Atlantic hurricane best track data base (HURDAT), Harville (2009) classified the hurricane tracks over the Appalachians into four types (also briefly summarized in Rostom and Lin 2015): (a) Type A: approximately perpendicular to the mountains from east to west, (b) Type B: parallel to the mountain along the eastern side, (c) Type C: parallel to the mountain along the western side, and (d) Type D: similar to Type A, but from west to east. The above track types have been further divided into the following six subtypes (Liu et al. 2016): $A 1, A 2$, and $A 3$ with a right angle from east and $A B 1, A B 2, A B 3$ with a track between $A$ and $B$ and Type $D$ into two subtypes DC1, DC2 with a track between D and C. Hugo (1989) and Isabel (2003) were chosen for this study because both hurricanes belonged to Type AB2 (Liu et al. 2016) and impinged on the Appalachian Mountains at nearby locations from a similar angle, but produced significantly different rainfall amounts over the mountains, as revealed in the rainfall maps (WPC 2016). This makes it easier to compare the relative contribution from individual key ingredients for producing heavy orographic precipitation. 
Hurricane Hugo (1989) was generated on September 9 off the coast of Africa, developed to a tropical depression the next day and then reached hurricane intensity on September 13. Hugo made landfall near Charleston on the South Carolina coast at 04 UTC 22 September (denoted as 9/22/04Z) and then moved northwestward at $12 \mathrm{~m} \mathrm{~s}^{-1}$. After landfall, Hugo's eye passed the vicinity of Columbia at 9/22/08Z when it was weakening. By 9/22/12Z, Hugo passed the west side of Charlotte, North Carolina and was weakened to a tropical storm. Then, the storm continued moving northward while crossing the western Virginia, West Virginia, eastern Ohio and Pennsylvania by $9 / 23 / 00 \mathrm{Z}$ and transformed into an extratropical storm (Case and Mayfield 1990). Hugo was considered the most damaging hurricane that has affected the US since Camille (1969) and before 1992 (Powell et al. 1991).

Isabel (2003) originated from a tropical wave on September 1 off the coast of Africa (Lawrence et al. 2005). Hurricane Isabel reached category 5 intensity on September 11 and made landfall at 9/18/17Z near Drum Inlet, North Carolina as a category 2 hurricane (N. Lin et al. 2010). Hurricane Isabel weakened quickly after landfall (Zhao and Jin 2008). On 9/19/06Z, Isabel became a tropical storm and moved northwestward over North Carolina and Virginia to the northeast of West Virginia. On 9/19/12Z, it transitioned to an extratropical storm and moved over Ohio into Canada (N. Lin et al. 2010). Hurricane Isabel created about 3.6 billion dollars in damage (Lawrence et al. 2005) and caused 34 fatalities in North Carolina, Virginia and Maryland (Nolan et al. 2009).

\section{Model Description and Experimental Design}

The WRF model version 3.4 (Skamarock et al. 2008) is adopted for the numerical simulations. The WRF model is a three-dimensional, non-hydrostatic, fully compressible, numerical weather prediction model with terrain-following pressure $(\sigma-p)$ coordinates. The governing equations of the WRF model are written in flux form with conserved mass and dry entropy. In this study, the Runge-Kutta third-order time scheme and the third and fifth-order advection schemes are chosen for the horizontal and vertical integrations, respectively. The simulations use three nested domains (Fig. 1),

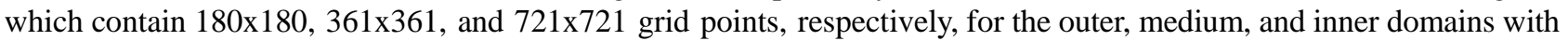
9,3 , and $1 \mathrm{~km}$ horizontal grid resolutions. The vertical grids are stretched from the surface to the model top (50 mb) with 48 levels. The open lateral boundary condition is adopted and the boundaries are kept far from the study area, as shown in Fig. 1.
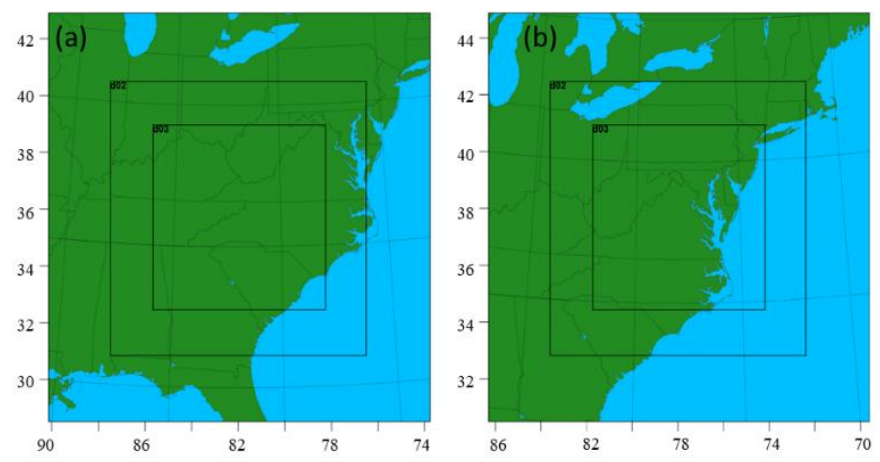

Figure 1. Domain configurations for (a) Hugo and (b) Isabel with three domains of 9, 3, and $1 \mathrm{~km}$ grid resolutions

Both hurricane simulations are initialized by the ECMWF reanalysis data as following: (1) For Hurricane Hugo (1989): Cases H9 (9/19/12Z - 9/23/00Z), H3 (9/21/00Z - 9/23/00Z), and H1 (9/21/12Z - 9/23/00Z) are conducted with 9, 3, and $1 \mathrm{~km}$ resolutions, respectively, and (2) For Hurricane Isabel (2003): Cases I9 (9/17/06Z - 9/20/00Z), I3 (9/17/12Z 9/20/00Z), and I1 (9/18/00Z - 9/20/00Z) are conducted with 9, 3, and $1 \mathrm{~km}$ resolutions, respectively. Table 1 summarizes the abbreviations of these cases, along with other terminologies adopted in this study. 
Table 1. Summary of Abbreviations

\begin{tabular}{|c|c|c|}
\hline Abbreviation & Full Name & Simulation Period \\
\hline H9 & $\begin{array}{l}\text { WRF-simulated Hugo (1989) with } 9 \mathrm{~km} \\
\text { resolution (D01 - outer domain) }\end{array}$ & $9 / 19 / 12 Z-9 / 23 / 00 Z$ \\
\hline H3 & $\begin{array}{l}\text { Same as H9 except with } 3 \mathrm{~km} \text { resolution } \\
\text { (D02 - medium domain) }\end{array}$ & $9 / 21 / 00 \mathrm{Z}-9 / 23 / 00 \mathrm{Z}$ \\
\hline $\mathrm{H} 1$ & $\begin{array}{l}\text { Same as H9 except with } 1 \mathrm{~km} \text { resolution } \\
\text { (D03 - inner domain) }\end{array}$ & $9 / 21 / 12 Z-9 / 23 / 00 Z$ \\
\hline I9 & $\begin{array}{l}\text { WRF-simulated Isabel (2003) with } 9 \mathrm{~km} \\
\text { resolution (D01 - outer domain) }\end{array}$ & $9 / 17 / 06 Z-9 / 20 / 00 Z$ \\
\hline I3 & $\begin{array}{l}\text { Same as I9 except with } 3 \mathrm{~km} \text { resolution } \\
\text { (D02 - medium domain) }\end{array}$ & $9 / 17 / 12 Z-9 / 20 / 00 Z$ \\
\hline I1 & $\begin{array}{l}\text { Same as } 19 \text { except with } 1 \mathrm{~km} \text { resolution } \\
\text { (D03 - inner domain) }\end{array}$ & $9 / 18 / 00 Z-9 / 20 / 00 Z$ \\
\hline ORI & Orographic Rain Index & $\mathrm{NA}$ \\
\hline MSLP & Minimum sea level pressure & NA \\
\hline $\mathrm{NHC}$ & National Hurricane Center & NA \\
\hline NLDAS & $\begin{array}{l}\text { North American Land Data Assimilation } \\
\text { System }\end{array}$ & NA \\
\hline TC & Tropical Cyclone & NA \\
\hline$V_{\max }$ & Maximum wind speed near surface & NA \\
\hline WPC & Weather Prediction Center & NA \\
\hline WRF model & Weather Research and Forecasting model & NA \\
\hline 9/22/04Z & 04 UTC 22 September & NA \\
\hline
\end{tabular}

The physics parameterization schemes chosen for these simulations are: (a) cumulus parameterization: Kain-Fritsch convective scheme (Kain 2004), (b) microphysics parameterization: Thompson microphysics scheme (Thompson et al. 2008), (c) planetary boundary layer (PBL) parameterization: YSU PBL scheme (Hong et al. 2006), (d) surface layer parameterization: revised WRF surface layer scheme (Jiménez et al. 2012), (e) land surface physics: Noah land surface model (Chen et al. 2001), (f) longwave radiation parameterization: RRTM scheme (Mlawer et al. 1997), and (f) shortwave radiation parameterization: New Goddard scheme (Mielikainen et al. 2012). Details of the above schemes can be found in the WRF user manual (Skamarock et al. 2008). The land use data is based on the USGS with (10', 5', 2') resolution for domains 1, 2, and 3, respectively, where $1^{\prime}=1$ arc-minute $=1^{\circ} / 60=(2 \pi R / 360)(\cos \phi) / 60 \sim 1.42 \mathrm{~km}, \mathrm{R}=6378 \mathrm{~km}$ is the Earth's radius, and $\phi \approx 37^{\circ} \mathrm{N}$ is the latitude for North Carolina. Thus, (10', 5', 2') equal to $(14.2 \mathrm{~km}, 7.1 \mathrm{~km}, 2.84 \mathrm{~km})$ approximately for North Carolina.

\section{Verification of Numerically Simulated Results}

\subsection{Track and Intensity}
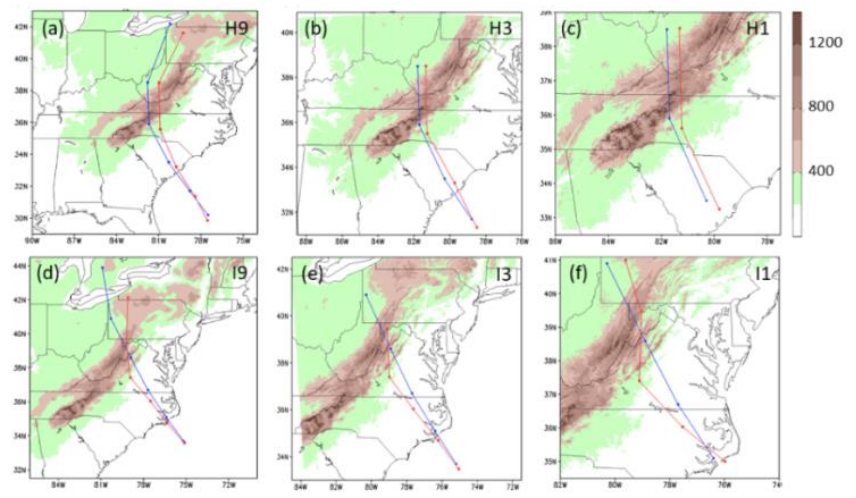

Figure 2. The six-hourly tracks for Hurricane Hugo simulated by (a) H9: 9-km resolution (9/21/18Z - 9/23/00Z), (b) H3: same as (a) except with 3-km resolution (9/22/00Z - 9/22/18Z), and (c) H1: same as (a) except with 1-km resolution (9/22/06Z - 9/22/18Z); and for Hurricane Isabel simulated by (d) I9: 9-km resolution (9/18/12Z - 9/19/18Z), (e) I3: same as (d) except with 3-km resolution (9/18/12Z - 9/19/12Z), and (f) I1: same as (d) except with 1-km resolution (9/18/18Z 9/19/18Z). The observed hurricane track is based on NHC's six-hourly Atlantic hurricane best track database (HURDAT) (blue) 
In this subsection, the simulated track and intensity (e.g., minimum sea level pressure and maximum surface wind speed) for Hurricanes Hugo (1989) and Isabel (2003) are verified by observations and used to estimate some common ingredients for heavy orographic rain. The simulated Hugo's tracks in H9 (9/21/18Z - 9/23/00Z), H3 (9/22/00Z - 9/22/18Z) and H1 (9/22/06Z - 9/22/18Z) match the NHC best track reasonably well in all domains (Fig. 2).

The simulated Hugo's landfalls lagged behind that of observed slightly, however, it was less than $1 \mathrm{~h}$ with the farthest landfall location, which was approximately $60 \mathrm{~km}$ south of that observed for all domains (H9, H3, and H1). The simulated Hurricane Isabel's tracks in I9 (9/18/12Z - 9/19/18Z), I3 (9/18/12Z - 9/19/12Z) and I1 (9/18/18Z - 9/19/18Z) match the best track reasonably well until it moved closer to the Appalachian Mountains. The simulated Isabel's landfalls lagged behind that observed, however, they were less than $1 \mathrm{~h}$ with the farthest landfall location approximately $40 \mathrm{~km}$ south of that observed for all domains (I9, I3, and I1). The simulated Isabel near the mountain was about $100 \mathrm{~km}$ to the southwest of that observed, made a right turn and remained on the east side of the best track. In short, the simulated track errors for both Hugo and Isabel are small in all domains for both hurricanes. The simulated tracks are then used to estimate the moving speed $\left(c_{s}\right)$, which was 12.5 knots $\left(\sim 6.25 \mathrm{~ms}^{-1}\right)$ for Hugo. It traveled at approximately $42 \%$ faster than that of Isabel at about 8.8 knots $\left(\sim 4.4 \mathrm{~ms}^{-1}\right)$. These moving speeds will be used to estimate the ORI in Sec. 5.

The simulated and observed Hugo's minimum sea-level pressures (MSLPs) and maximum surface wind speeds $\left(V_{\max }\right)$ are shown in Figs. 3a and 3b. Since our focus is on the vicinity of the mountain area, the comparison starts at 9/22/06Z for Hugo. The evolutions of the simulated MSLP and $V_{\max }$ of Hugo match those observed closely. The simulated H1 landfall lagged $2 \mathrm{~h}$ of that observed (9/22/08Z) and $V_{\max }(92 \mathrm{kts}$, where kts stands for knots) was slightly larger than that observed (85 kts) (Fig. 3a). The simulated $V_{\max }(91 \mathrm{kts})$ of $\mathrm{H} 3$ was also larger than that observed, while the simulated $V_{\max }$ (74 kts) of H9 was much smaller than that observed. At 9/22/12Z, when the simulated Hugo moved closer to the Appalachians, its $V_{\max }$ of $\mathrm{H} 1$ weakened to $55 \mathrm{kts}$. The simulated $V_{\max }$ 's of H1, H3, and $\mathrm{H} 9$ storms were 50, 45, and $44 \mathrm{kts}$, respectively. As expected, all simulated storms were weakened when they moved to the vicinity of the mountains, as also seen in the observation. The simulated storms continued to weaken while they crossed over the mountain peak to the lee (western) side, which were consistent with those observed. During the first $9 \mathrm{~h}$ after landfall $(9 / 22 / 06 \mathrm{Z}-9 / 22 / 15 \mathrm{Z})$, the simulated MSLPs of H1, H3, and H9 storms were 972, 972, and $970 \mathrm{mb}$, respectively, which were all higher (i.e., weaker) than those observed (Fig. 3b). At 9/22/12Z, the MSLPs simulated by H9, H3, and H1 are 977, 977, and $971 \mathrm{mb}$, respectively, which were in close agreement with observed MSLP (975 mb). During the period of 9/22/18Z - 9/23/00Z, the simulated MSLPs were very close to those observed.
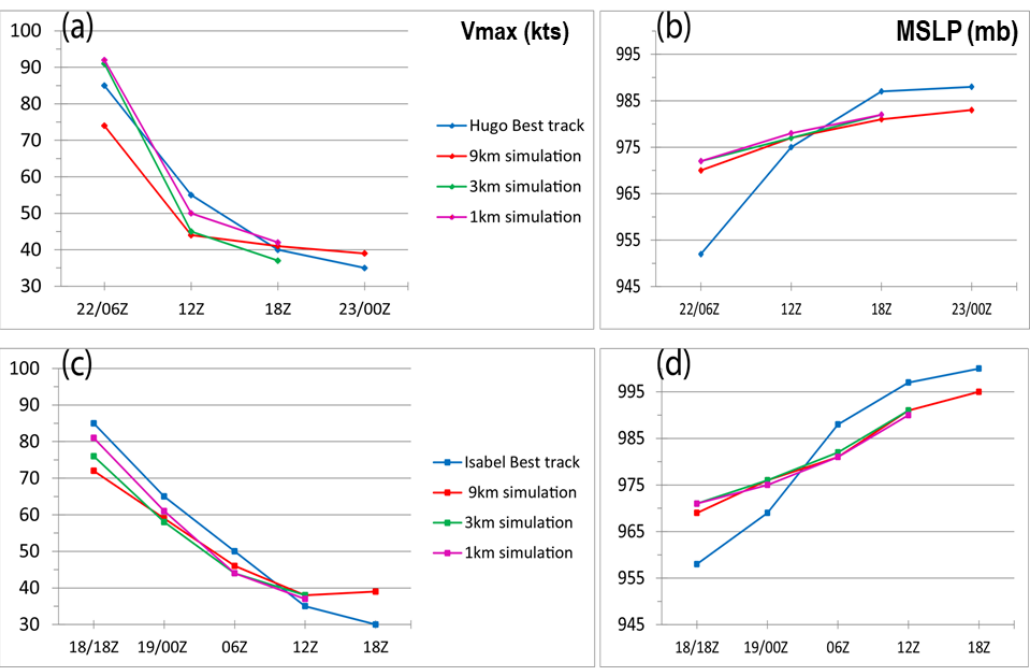

Figure 3. Observed and simulated (a) maximum surface wind speed ( $V_{\max }$; in knots) and (b) minimum sea level pressure (MSLP; in mb) by H9 (9 km), H3 (3 km), and H1 (1 km) simulations for Hugo. Panels (c) and (d) are the same as (a) and (b), respectively, but for Isabel (I9, I3, and I1). The observed $V_{\max }$ and MSLP were based on NHC's six-hourly Atlantic hurricane best track database (HURDAT)

The simulated and observed MSLPs and $V_{\max }$ for Isabel are shown in Figs. 3c and 3d. The comparison starts at 9/18/18Z when the Isabel made landfall. The simulated $V_{\max }$ 's of I9, I3, and I1 at 9/18/18Z (about $1 \mathrm{~h}$ after landfall) were 72, 76, and $81 \mathrm{kts}$, respectively, which were all smaller than that observed ( $85 \mathrm{kts}$ ) (Fig. 3c). Starting at 9/19/00Z, the simulated $V_{\max }$ 's of Isabel were smaller, but very close to those observed. Similar to the simulations of Hugo, the simulated MSLPs of Isabel were higher (i.e., weaker) than those observed in the first $10 \mathrm{~h}$, but were close to those observed within $\sim 11 \mathrm{mb}$ right after landfall and then within $\sim 6 \mathrm{mb}$ afterwards (Fig. 3d). 
In summary, the simulated tracks and intensities of Hugo and Isabel compared reasonably well with observations, which, in turn, produced rainfall patterns and accumulated precipitation comparable to those observed.

\subsection{Reflectivity and Accumulated Precipitation}

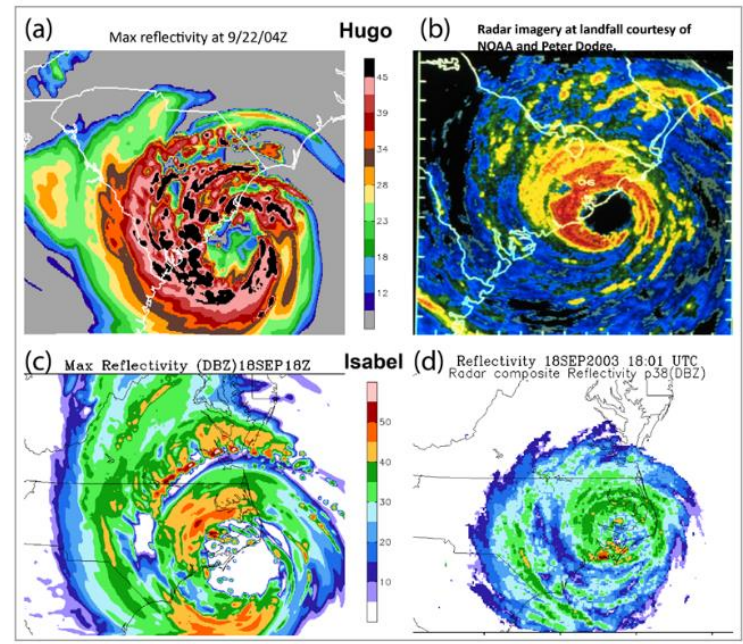

Figure 4. (a) H3 simulated reflectivity at 9/22/04Z/1989, (b) radar imagery at landfall for Hugo (courtesy of NOAA and Peter Dodge), (c) I3 simulated reflectivity at 9/18/18Z/2003 and (d) radar composite reflectivity at landfall for Isabel

Figure 4 shows the H3 (I3) simulated (i.e. simulations with 3-km resolution) reflectivity and rainfall pattern of Hugo (Isabel) compared reasonably well with the observed radar reflectivity composite at landfall around 9/22/04Z/1989 $(9 / 18 / 18 Z / 2003)$.

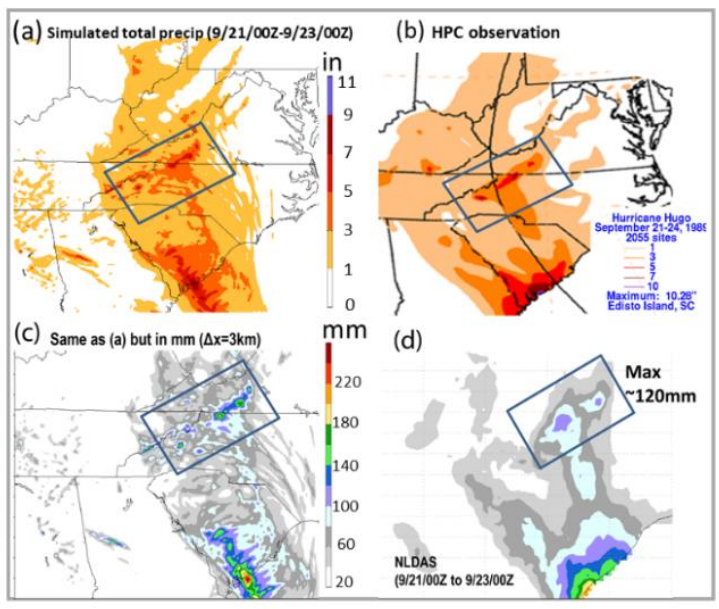

Figure 5. (a) The H3 simulated accumulated precipitation for Hugo (1989) from 9/21/00Z - 9/23/00Z (in inches), (b) WPC observed accumulated precipitation (in inches) from 9/21/00Z - 9/24/00Z, (c) same as (a) except in mm, and (d) accumulated precipitation (in $\mathrm{mm}$ ) from $9 / 21 / 00 \mathrm{Z}-9 / 23 / 00 \mathrm{Z}$ by NLDAS. Note that $1,3,5,7,10$, and 10.28 inches approximately equal to $25.4,76.2,127.0,177.8,254.0$, and $261.1 \mathrm{~mm}$, respectively

The H3-simulated accumulated precipitation is shown in Fig. 5a (in inches) and Fig. 5c (in mm), which can be compared with those observed by the Weather Prediction Center (WPC) (Fig. 5b; in inches) and the North American Land Data Assimilation System (NLDAS) (Fig. 5d; in mm). Note that the NLDAS (LDAS 2015) was constructed with quality-controlled, and temporally and spatially consistent, land-surface model datasets from the best available observations and reanalyses to support modeling activities. The simulated accumulated precipitation was from $9 / 21 / 00 Z-$ 9/23/00Z, while the NLDAS observed accumulated precipitation was extended farther to 9/24/00Z. However, the accumulated precipitation over the Appalachians after 9/23/00Z was negligible when compared to the total accumulated precipitation because by then the storm has already moved to the northern part of Pennsylvania. The observed accumulated precipitation revealed two maximum areas (Fig. 5b). The first maximum of accumulated precipitation area 
was in the southeastern part of South Carolina right after the Hugo made the landfall, while it still had strong surface winds up to $42 \mathrm{kts}$ with about $178 \mathrm{~mm}$ of rain. The second maximum of accumulated precipitation area with $254 \mathrm{~mm}$ can be found in northern North Carolina and southern Virginia, along the eastern slope of the Appalachian Mountains. The NLDAS data shows the same rainfall pattern as that observed, except that it underestimated the amount of rainfall to be $\sim 120 \mathrm{~mm}$ (Fig. 5d). The $\mathrm{H} 3$ simulated rainfall pattern and maximum location compared well with those observed by WPC and the NLDAS data. Its quantitative precipitation forecast is closer to the observations, compared to the NLDAS data, which significantly underestimated the rainfall.

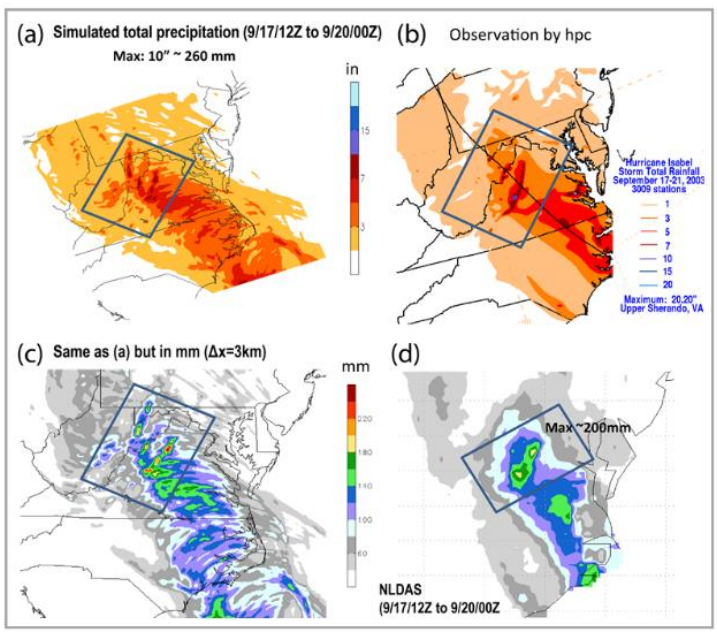

Figure 6. (a) The I3 simulated accumulated precipitation for Isabel (2003) from 9/17/12Z - 9/20/00Z (inch), (b) WPC observed accumulated precipitation (in inches) from 9/17/00Z - 9/21/00Z, (c) same as (a) except inmm, and (d) accumulated precipitation (in $\mathrm{mm}$ ) from $9 / 17 / 12 \mathrm{Z}-9 / 20 / 00 \mathrm{Z}$ by the NLDAS. Note that $1,3,5,7,10,15,20$, and 20.20 inches approximately equal to $25.4,76.2,127.0,177.8,254.0,381.0,508.0$, and $513.1 \mathrm{~mm}$, respectively

Figure 6 is similar to Fig. 5 except for Isabel (2003). The simulated I3 accumulated precipitation (Figs. 6a - in inches, and $6 \mathrm{c}-$ in $\mathrm{mm}$ ) and the NLDAS data were from 9/17/12Z - 9/20/00Z (Fig. 6d), while the WPC observation lasted until 9/21/00Z (Fig. 6b). For Hugo, the inclusion of an additional day does not show significant precipitation affecting the Appalachians because the storm has already moved out of the Appalachian Mountain area and reached New York State by 9/20/00Z. Observed accumulated precipitation associated with Isabel's eye and rain bands was about $127 \mathrm{~mm}$ (Fig. 6b). The I3-simulated maximum rainfall area is confined along the mountain slope of western Virginia with $\sim 254 \mathrm{~mm}$, indicating the rain enhancement by the mountains. Note that a rainfall amount of $508 \mathrm{~mm}$ was observed at one location in Upper Shenandoah, Virginia. The NLDAS data (Fig. 6c) shows the same rainfall pattern as that observed, but had a maximum rainfall of $200 \mathrm{~mm}$ and missed one spot where there was about $508 \mathrm{~mm}$. The I3-simulated rainfall pattern and maximum rainfall location compared well with both observations and NLDAS data. On the other hand, the I3 quantitative rainfall forecast missed the location in Upper Shenandoah with $508 \mathrm{~mm}$. This discrepancy appears to be partially related to the relatively sparse rain gauges (e.g., see Fig. 3 of Hart and Evans 2001), but the rest of the mountain slope with 254 $\mathrm{mm}$ of rain was close to that observed and the NLDAS data.

Note that in Figs. 5 and 6, the H3 and I3 simulated accumulated precipitation, instead of the H1 and I1 (1-km resolution) simulated results, were used for comparison because the domains of H1 and I1 were too small to represent the total accumulated precipitation along the entire storm track from landfall till their passages over the Appalachians. In order to demonstrate the quantitative precipitation forecast capability of the 1-km resolution simulations, the $\mathrm{H} 1$ and I1 simulated results are shown in Fig. 7, which resulted maximum accumulated precipitation of $\sim 203 \mathrm{~mm}$ and $254 \mathrm{~mm}$, respectively, over the mountainous area. These results were almost identical to those simulated by the $3-\mathrm{km}$ resolution runs (H3 and I3) (Figs. 5 and 6). The 1-km resolution runs (H1 and I1) provided extremely detailed rainfall distribution with local rainfall maxima strongly affected by local mountain peaks and valleys. This helps us choose local areas for testing the ORI to be proposed in Sec. 5.

\section{Common Ingredients and a Modified Orographic Rain Index (ORI) for Heavy Orographic Rainfall Associated With Hugo (1989) and Isabel (2003)}

Based on the ingredient argument (Doswell et al 1996), Lin01 and Lin (2007) proposed that heavy orographic precipitation is controlled by Eq. (1), which, in turn, requires significant contributions from any combination of the following common ingredients: (1) a high precipitation efficiency of the incoming airstream $(\varepsilon),(2)$ a strong low-level 
flow $\left(V_{H}\right),(3)$ a steep mountain slope (large $\left.\nabla h\right)$, (4) a strong orographic lifting over the upslope (large $\left.V_{H} \cdot \nabla h\right),(5)$ a strong synoptically forced upward motion (large $w_{\text {env }}$; e.g., low-level convergence or upper-level divergence), (6) an unstable airstream upstream (e.g., conditional or potential instability), (7) a very moist, upstream flow (large $q_{v}$ or RH), (8) a large convective system $\left(L_{s}\right)$, and (9) a slow movement of the convective system $\left(c_{s}\right)$. These common ingredients will be examined using the orographic and flow parameters simulated of two selected hurricanes, Hugo (1989) and Isabel (2003), to help select some key common ingredients for constructing the ORI for predicting heavy orographic TC rain, which will be proposed in Sec. 5.2.

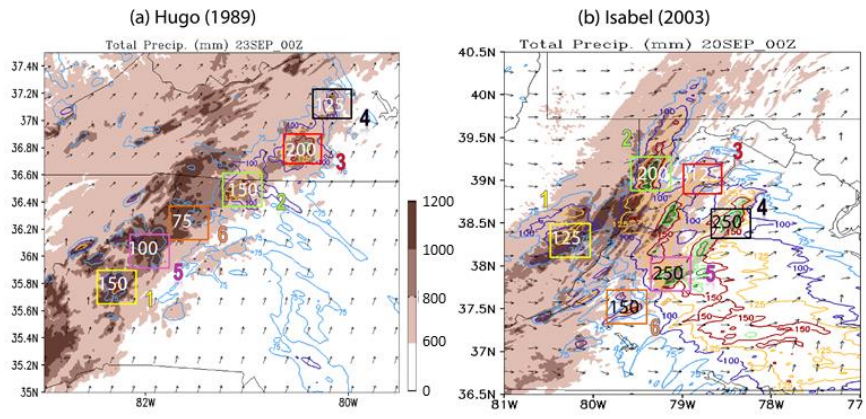

Figure 7. (a) H1 (Hugo 1-km resolution) simulated maximum accumulated rainfall in each of the 6 areas with localized maximum rainfall over the upslope of the Appalachians from 9/22/06Z - 9/22/18Z/1989, and (b) Same as (a) except for I1

(Isabel 1-km resolution) simulation from 9/18/18Z - 9/19/18Z/2003

Figure 7a shows the H1 (Hugo 1-km resolution) simulated maximum accumulated rainfall in each of the six areas over the upslope of the Appalachians with localized maximum rainfall from 9/22/06Z - 9/22/18Z/1989, while Fig. 7b shows the maximum accumulated rainfall as those in Fig. 7a except for I1 (Isabel 1-km resolution) simulation from 9/18/18Z $9 / 19 / 18 Z / 2003$. Isabel has produced a maximum rainfall of $\sim 250 \mathrm{~mm}$, which is $25 \%$ more than that of Hugo. This difference will also be explained by examining the key ingredients for heavy orographic rainfall.

\subsection{Comparison of the Commo Ingredients Between Hugo (1989) and Isabel (2003)}
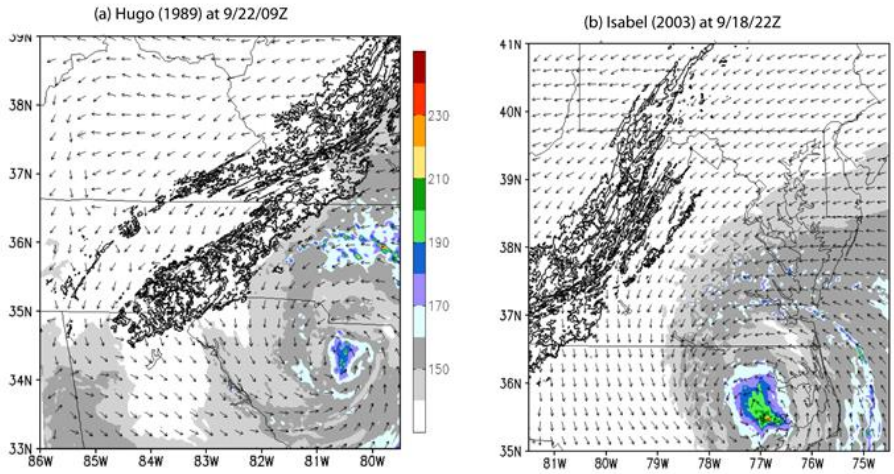

Figure 8. Simulated vertically integrated total water mixing ratio (water vapor, cloud water, cloud ice, rain, snow and graupel) (in mm) at, (a) 9/22/09Z by H1 for Hugo (1989) and at (b) 9/18/22Z by I1 for Isabel (2003). Topography contoured in black

The first ingredient to be examined is whether the incoming flow contains a large precipitation efficiency (large $\varepsilon$ ), which is defined as the ratio of total precipitation to the total available moisture of a precipitating system (e.g., Lin 2007). The estimated precipitation efficiencies of Hugo and Isabel were $72 \%$ and 97\%, respectively, which are estimated by dividing the averaged total precipitation (Fig. 7) by the averaged total water mixing ratio (Fig. 8) over the six areas with local maximum rainfall as shown in Fig. 7, based on $\mathrm{H} 1$ and $\mathrm{I} 1$ simulations, respectively. These precipitation efficiencies are considered large.

The second ingredient to be examined is a large low-level flow $\left(V_{H}\right)$. These strong low-level flow were associated with strong tangential wind of the TC vortex, which were the key in generating strong orographic lifting (large $w$ or $w_{\text {oro }}$ more specifically), as implied by Eq. (1) since $w_{\text {oro }} \approx V_{H} \cdot \nabla h$, where $V_{H}$ is the horizontal wind speed upstream of the mountain. In fact, for a three-dimensional flow over a mountain, $w_{\text {oro }} \approx V_{H} \cdot \nabla h \approx V_{n} \partial h / \partial n$. In other words, the orographic lifting of the incoming flow was contributed by the wind component normal to the local mountain range. 

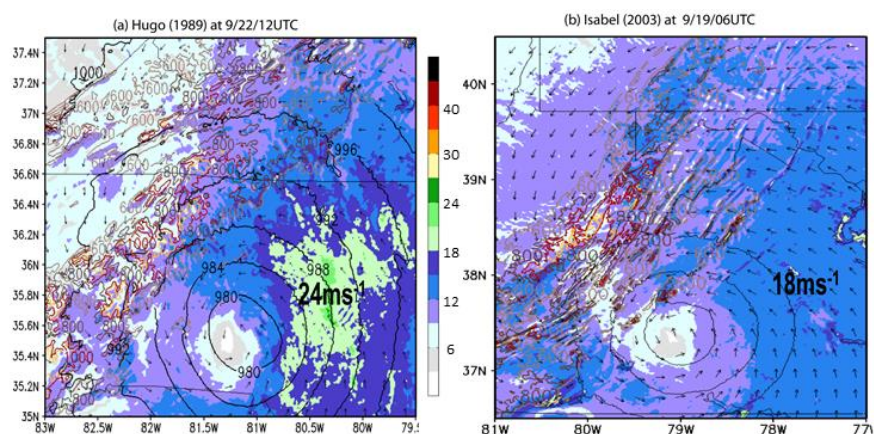

Figure 9. The $\mathrm{H} 1$ and $\mathrm{I} 1$ simulated $10-\mathrm{m}$ total horizontal wind fields normal to the local mountain range $\left(V_{n}\right)$ at $(\mathrm{a})$ 9/22/12Z for Hugo (1989) and (b) 9/19/06Z for Isabel (2003). The topography contours are 600, 800, 1000, and 1200

$\mathrm{m}$

Figure 9 shows the $\mathrm{H} 1$ and $\mathrm{I} 1$ simulated $10-\mathrm{m}$ total wind fields normal to the local mountain range $\left(V_{n}\right)$ were $24 \mathrm{~ms}^{-1}$ at 9/22/12Z for Hugo (1989) and $18 \mathrm{~ms}^{-1}$ at 9/19/06Z for Isabel (2003), which were strong. This may lead to heavy orographic rain when Hurricanes Hugo or Isabel was moving toward the Appalachians.

The third ingredient to be examined is a steep terrain (large $\nabla h$ ), which may be estimated by using the mountain slope represented in the 1-km grid resolution (H1 and I1). The six areas of localized maximum rainfall for both Hugo and Isabel are shown in Fig. 7 . The slope is estimated to reach an average slope of $\sim 0.03(0.6 \mathrm{~km} / 20 \mathrm{~km})$, which was gentle, but was still steep enough to lift the incoming flow for producing heavy precipitation upstream because the incoming wind flow $\left(V_{n}\right)$ is strong.

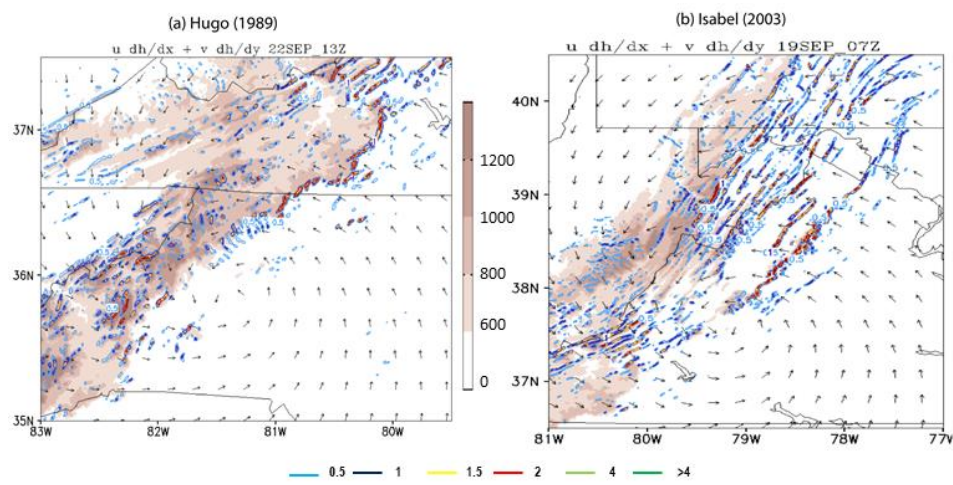

Figure 10. The H1 and I1 simulated orographically forced vertical motion ( $w_{\text {oro }}$, color bar in $\mathrm{m} \mathrm{s}^{-1}$ ) at $10 \mathrm{~m}$ above the mountain surface (contours, in $\mathrm{m} \mathrm{s}^{-1}$ ) at (a) 9/22/13Z for Hugo (1989) and (b) 9/19/07Z for Isabel (2003). Topography is shaded (in m)

In fact, the second and third ingredients can be examined together by the fourth ingredient, $w_{\text {oro }} \approx V_{H} \cdot \nabla h \approx V_{n} \partial h / \partial n$, where $V_{n}$ is the component of the incoming flow normal to the local topography. Using H1 and I1 simulated $V_{n}$ and $\partial h / \partial n$, the $w_{\text {oro }}$ are calculated as shown in Figs. 10a and 10b at 9/22/13Z and Isabel (2003) at 9/19/07Z, respectively. A significant portion of the orographic lifting were higher than $0.5 \mathrm{~m} \mathrm{~s}^{-1}$, which were strong.

The fifth ingredient to be examined is the environmentally forced upward motion $\left(w_{\text {env }}\right)$, which together with $w_{\text {oro }}$ make up the total vertical motion $w$ (or $w_{\text {total }}$ ), assuming a linear superposition. The $w_{\text {env }}$ is often associated with instabilities, such as conditional or potential instability, and/or large-scale forcing, such as low-level convergence and upper-level divergence. Figure 11 shows H1 and I1 simulated $w_{\text {total }}$ for Hugo (1989) at 9/22/13Z and for Isabel (2003) at 9/19/07Z, respectively. A comparison of Figs. 9 and 10 shows that the areas of $w_{\text {total }}$ and $w_{\text {oro }}$ match very well, which implies that $w_{\text {total }}$ was dominated by $w_{\text {oro }}$. 


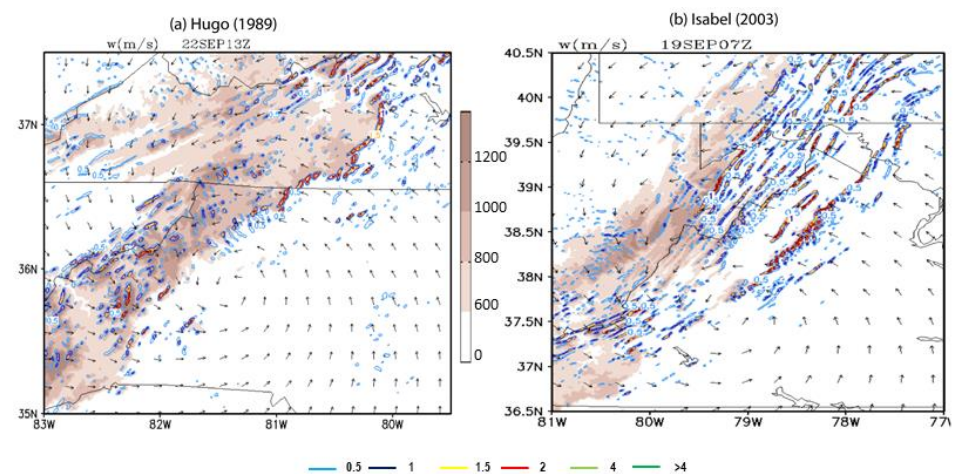

Figure 11. The $\mathrm{H} 1$ and $\mathrm{I} 1$ simulated total vertical motion $\left(w_{\text {total }}\right.$, in $\left.\mathrm{m} \mathrm{s}^{-1}\right)$ at $10 \mathrm{~m}$ above the Mountain surface (contours, in $\mathrm{m} \mathrm{s}^{-1}$ ) at (a) 9/22/13Z for Hugo (1989) and (b) 9/19/07Z for Isabel (2003). Topography is shaded (in m)

The sixth ingredient to be examined is the existence of instabilities in the airstream upstream. The H1 and I1 simulated surface- $850 \mathrm{mb}$ CAPE distributions for Hugo and Isabel, respectively, are shown in Fig. 12
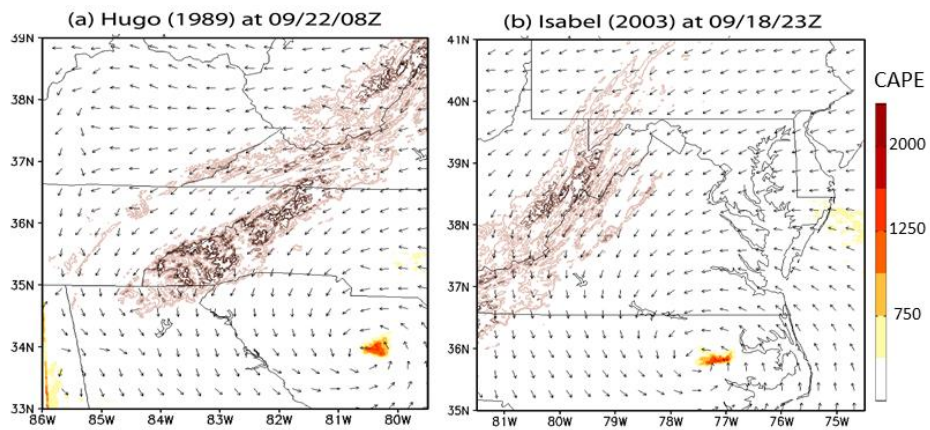

Figure 12. The surface-850mb CAPE distribution for (a) Hugo (1989) at 9/22/08Z and (b) Isabel (2003) at 9/18/23Z as simulated by $\mathrm{H} 1$ and I1, respectively. Topography contours are 600, 800, 1000, and 1200m
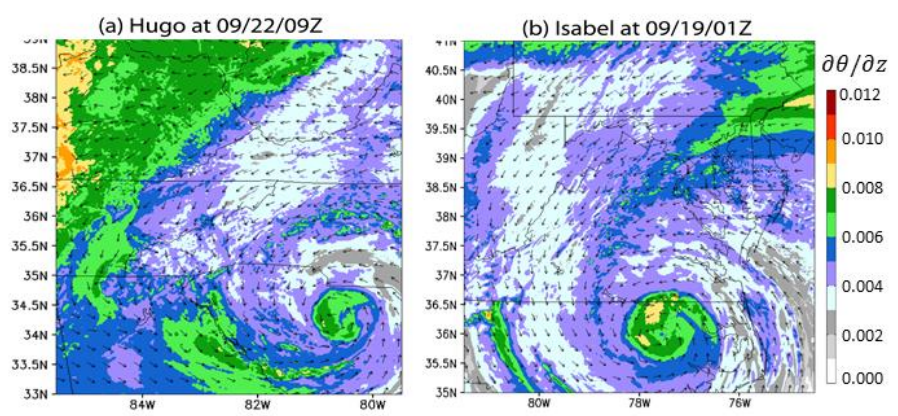

Figure 13. The surface - $850 \mathrm{mb} \partial \theta_{e} / \partial z$ distribution for (a) Hugo (1989) at $9 / 22 / 09 \mathrm{Z}$ as simulated by $\mathrm{H} 1$ and (b) Isabel (2003) at $9 / 19 / 01 \mathrm{Z}$ as simulated by I1. Note that all $\partial \theta / \partial z>0$

For both hurricanes, the CAPE values were smaller than $500 \mathrm{~J} \mathrm{~kg}^{-1}$ after landfall except near the eye, which also decreased to less than $500 \mathrm{~J} \mathrm{~kg}^{-1}$ within an hour. These CAPE values are considered small, which were caused by the strong vertical mixing associated with strong, deep convection embedded in the hurricanes. Unlike the midlatitude thunderstorm, this implies that conditional instability played an insignificant role in the formation of heavy orographic rainfall associated with Hugo and Isabel. The existence of potential instability is examined by checking $\partial \theta_{e} / \partial z<0$ in the surface-850mb layer using the simulated H1 and I1 equivalent potential temperature fields at $9 / 22 / 09 \mathrm{Z}$ and 9/19/01Z, respectively. The results indicate no negative values, as shown in Fig. 13. Therefore, the potential instability plays no significant role in the formation of heavy orographic rainfall associated with Hugo and Isabel.

A high moisture upstream is the seventh ingredient for producing heavy orographic rainfall, which remains to be examined. Either the water vapor mixing ratio $\left(q_{v}\right)$ or the relative humidity $(\mathrm{RH})$ upstream of the mountain may be used to represent the moisture content (Lin01; Lin et al. 2002). Near the maximum rainfall areas on the Appalachians, 
the averaged water vapor mixing ratio $\left(q_{v}\right)$ values were $17 \mathrm{~g} / \mathrm{kg}$ and $14 \mathrm{~g} / \mathrm{kg}$ for Hugo and Isabel, respectively, which are considered relatively high moisture. The averaged RH values are $86 \%$ and $80 \%$ for Hugo and Isabel, respectively, were high during the passages of Hugo and Isabel over the Appalachian Mountains (Fig. 14).
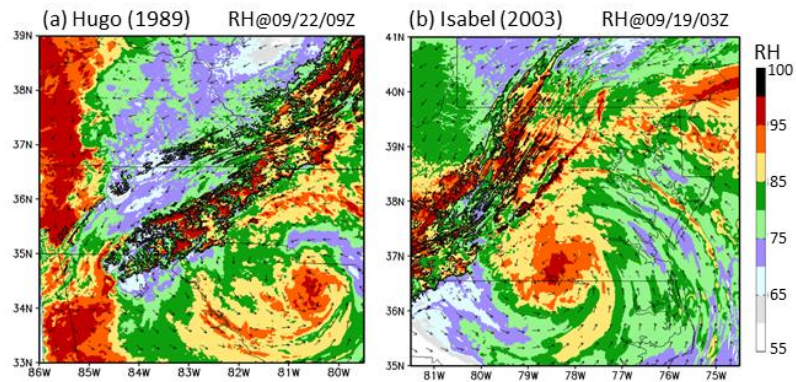

Figure 14. The relative humidity (RH; in \%) fields simulated for, (a) Hugo (1989) by H1 at $9 / 22 / 09 \mathrm{Z}$ and (b) Isabel (2003) by I1 at 9/19/03Z. Topography contoured in black

The eighth ingredient to be examined is the large size of convection system $\left(L_{s}\right)$, which is characterized by the TC size in the current situation. Based on the simulated reflectivity and observed radar imagery (Fig. 4), both Hugo and Isabel had a large convective system with an $L_{s}$ of about $150 \mathrm{~km}$. The ninth ingredient to be examined is the moving speed of the convective system $\left(c_{s}\right)$. The hurricane's moving speed is estimated by dividing the distance by the time the storm took to travel over the area. Hugo traveled at approximately $12.5 \mathrm{knots}\left(\sim 6.25 \mathrm{~ms}^{-1}\right)$, about $42 \%$ faster than Isabel's approximate moving speed of 8.8 knots $\left(\sim 4.4 \mathrm{~ms}^{-1}\right)$, which caused the smaller amounts of rainfall produced by Hugo compared to that produced by Isabel.

Based on the above analysis, we conclude that six of the nine ingredients make significant contributions from both hurricanes: high precipitation efficiency of the incoming airstream, low-level flow, strong orographic lifting, high moisture flow, large convective system, and slow movement of the hurricane. These key ingredients are largely responsible for the heavy rainfall produced in both cases with weak or no conditional or potential instabilities available. This finding is similar to that found for Typhoon Morakot (2009) over Taiwan's Central Mountain Range, where a huge amount of rain was caused by its slow movement, strong terrain lifting, the confluence between the typhoon's outer circulation and the southwesterly monsoonal current (e.g., Huang and Lin 2014; Hong et al., 2010; C.-Y. Lin et al. 2011; Chien and Kuo, 2011; Wu et al., 2011; Yen et al., 2011), rather than due to a large CAPE, like that found in Supertyphoon Bilis (2000) over CMR (Witcraft et al., 2005). Hugo had a slightly higher moisture and a stronger low-level jet, but moved much faster and had lower precipitation efficiency, and therefore produces $25 \%$ less total rainfall, compared to Isabel.

\subsection{Application of a Modified Orographic Rain Index (ORI) for Heavy Orographic TC Rain}

As discussed in the Introduction, since heavy orographic rain enhancement during the passage of TCs over a mesoscale mountain may be determined by different combinations of common ingredients, we modify Lin01's ORI as

$$
O R I=\left(V_{n} \frac{\partial h}{\partial n}\right)\left(\frac{L_{s}}{c_{s}}\right)(R H)
$$

In the above equation, $V_{n} \partial h / \partial n \approx w_{\text {oro }}$, where $V_{n}$ is the wind speed in the direction normal to the local mountain range $(n)$, $R H$ is the relative humidity of the incoming airflow, and $L_{s} / c_{s}$ is the duration of the precipitation system passing over a fixed location on mountain surface. The $V_{n}$ is calculated at a location where the precipitating system is in the vicinity of the mountain. Since the precipitation efficiency is relatively high in the vicinity of a tropical cyclone, it is assumed as unity in the ORI. Figure 15a shows the H3 (Hugo with 3-km resolution) simulated 10-m $V_{n}$ wind field at 9/22/12Z, while Fig. 15b shows that simulated by I3 (Isabel with 3-km resolution) at 9/19/06Z. 


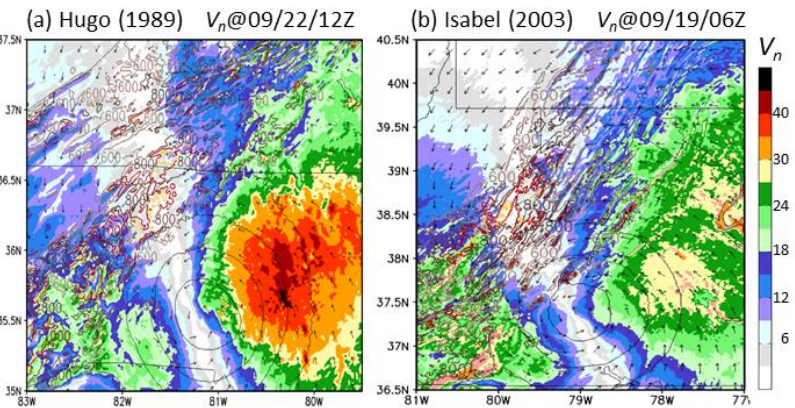

Figure 15. The $\mathrm{H} 1$ and $\mathrm{I} 1$ simulated $10-\mathrm{m}$ horizontal wind normal to the mountain range $\left(V_{n} ; \mathrm{ms}^{-1}\right)$ at (a) 9/22/12Z for Hugo (1989) and (b) 9/19/06Z for Isabel (2003). Topography is contoured at 600, 800, 1000, and $1200 \mathrm{~m}$

The use of $V_{n}$ field is to differentiate the areas where the wind blows perpendicular to the local mountain range from that blows parallel to it. In other words, the strength of orographic lifting is sensitive to the impinging angle, which reaches the maximum when the impinging angle is $90^{\circ}$. That is why the normal component of the wind is chosen for calculating the ORI. The maximum mountain steepness $d h / d n$ is estimated at each local location. The storm moving speeds $\left(c_{S}\right)$ were estimated earlier in Sec. 5.1 as 12.5 knots $\left(\sim 6.25 \mathrm{~ms}^{-1}\right)$ and $8.8 \mathrm{knots}\left(\sim 4.4 \mathrm{~ms}^{-1}\right)$ for Hugo and Isabel, respectively. Approximately, Hugo traveled at about $42 \%$ faster than Isabel, and $L_{s}$ was estimated by the averaged diameter of the tropical cyclone based on the numerically simulated radar reflectivity field.

To test the ORI, six regions, which were based on the local maximum rainfall as shown in Fig. 7, were chosen for each hurricane. For each region, the $\mathrm{H} 1$ and $\mathrm{I} 1$ simulated hourly rainfall rate $(R)$, normal wind speed $\left(V_{n}\right), R H, L_{s}$, and $c_{s}$ are estimated. Figures $16 \mathrm{a}$ and $16 \mathrm{~b}$ show the ORI versus the observed hourly rainfall rate for Hugo and Isabel, respectively. All 12 regions in both Hugo and Isabel indicate that there was a strong correlation between the ORI and rainfall rate. Note that one should pay attention to the overall, longer-term ORI evolution, instead of short-term variation (e.g., one or two hours) because there was a possibility that a dry spell might exist in a short period (e.g., $1 \mathrm{~h}$ ) during a heavy rain episode. For example, in Region 1 at 9/22/11Z and Region 3 at 9/22/12Z during Hugo's passage, and in Region 3 at 9/19/08Z during Isabel's passage, there was no rain between the heavy rain episodes, but the ORI did not show a dramatic decrease. The reason that the ORI did not correspond very well to the sudden drops in rainfall rate during these short time periods is explained by the fact that the microphysical processes at these local locations were not reflected immediately in the estimation of ORI.

All the ORI evolutions in the 12 regions of both hurricanes shared the same characteristics, i.e., the ORI evolution increased smoothly until it reached a maximum near the time of maximum rainfall rate. If there were several maxima occurred in a certain rainy period, then after reaching one maximum, it then decreased smoothly back to a minimum at the end of the rainy period. Thus, the ORI should be considered for the entire rainy period, instead of just for one specific rainy episode since it might lead to incorrect predictions. In the current study, the parameters contributing to the ORI, such as $L_{s}$ and $c_{s}$, were fixed for each storm and the slope was fixed for the location, leaving the ORI to be controlled by only two parameters, $V_{n}$ and $R H$, at each location. Results show that overall the ORI did correlate with $V_{n}$ and $R H$ very well, although it was more sensitive to $V_{n}$ and less sensitive to $R H$. Since fine resolution operational forecasts are still unavailable, we extended our study to derive the ORI with output from the coarser resolution (9 km) runs, such as that shown in Fig. 17. Figure 17 was the same as Fig. 16 except with two differences: (1) all inputs were taken from $\mathrm{H} 9$ and $\mathrm{I} 9$, and (2) the simulated three hourly precipitation in both cases showed early signs of maximum rain so we started our ORI dates accordingly, which were 9/21/12Z - 9/22/18Z and 9/18/21Z - 9/19/21Z for Hugo and Isabel, respectively. The three-hourly output of the $9-\mathrm{km}$ resolution run made the ORI variation more rapid. For example, the $V_{n}$ might vary from $3 \mathrm{~m} \mathrm{~s}^{-1}$ in one output to $30 \mathrm{~m} \mathrm{~s}^{-1}$ in the next. Overall, we find that the ORI estimated from finer resolution model results still remained and the ORI may serve as an indicator for rainfall associated with tropical cyclones passing over mesoscale mountains. 

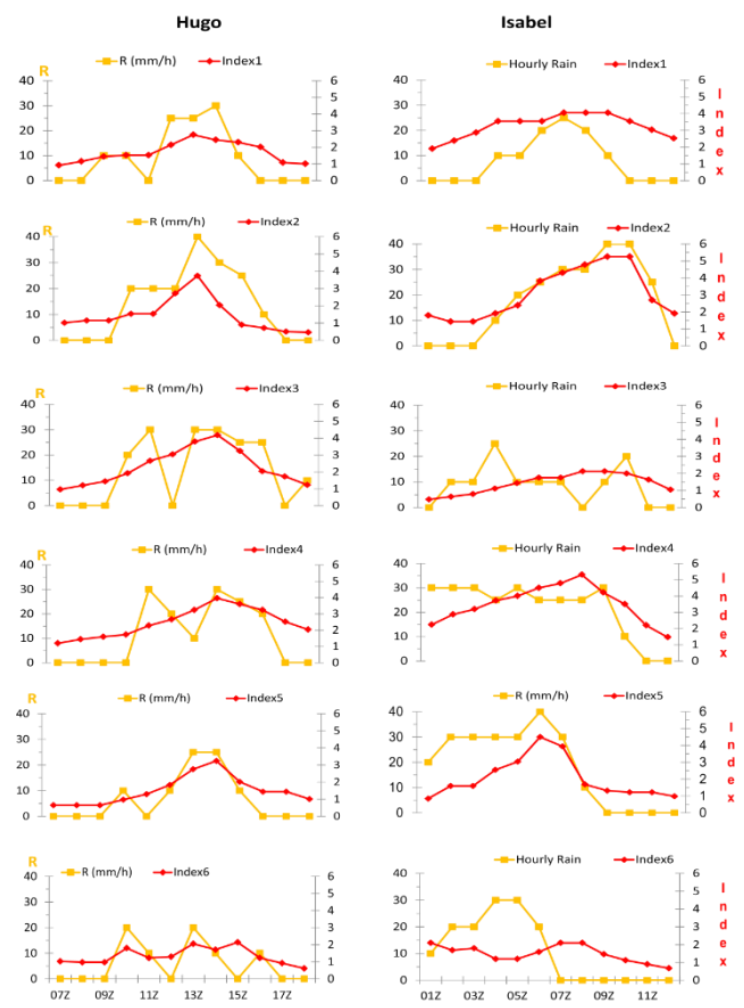

Figure 16. Estimated evolutions of the modified ORI (in red) for Hugo (1989) and Isabel (2003) in Regions 1-6, based on $\mathrm{H} 1$ and $\mathrm{I} 1$ simulated hourly rainfall rate $(R)$, magnitude $V_{n}$, and $R H$ from both hurricanes versus observed hourly rainfall rate $(\mathrm{mm} / \mathrm{h}$, in yellow) for Hugo (right) and Isabel (left). The period is $9 / 22 / 07 \mathrm{Z}$

- $18 \mathrm{Z}$ for Hugo and 9/19/01Z - $12 \mathrm{Z}$ for Isabel when the TC moves close to the local rainfall maximum region. The symbol "Index $i$ " in the figure panels denotes the ORI for local rainfall maximum region $i$

\section{Summary and Concluding Remarks}

In this study, the common ingredients for heavy orographic precipitation proposed by Lin01 and Lin (2007) are examined for orographic rainfall associated with the passage of Hurricanes Hugo (1989) and Isabel (2003) over the Appalachian Mountains. Hugo and Isabel were selected due to their similar impinging angles on the Appalachians and very different total rainfall. The WRF model was then used to simulate these two storms. The simulated tracks, wind and reflectivity fields and rainfall amounts and pattern compared reasonably well with observations. Quantitatively, the model-simulated maximum total rainfall $(200 \mathrm{~mm})$ of Hugo was close to the observation $(250 \mathrm{~mm})$, while the model-simulated maximum total rainfall $(250 \mathrm{~mm})$ of Isabel was only about half of that observed $(500 \mathrm{~mm})$. Note that the observed $500 \mathrm{~mm}$ maximum total rainfall occurred only in a very limited area, while the model-simulated average rainfall $(250 \mathrm{~mm})$ over the mountain slope compared reasonably well with that observed. The forecast error of the maximum total rainfall was attributed to the right turn of Isabel's simulated track.

The wind and precipitation fields associated with Hugo and Isabel were simulated by the WRF model with 1-km fine resolution (H1 and $\mathrm{I1}$ ) to examine the relative contributions of each individual ingredients in producing heavy orographic rainfall through detailed comparisons. It is found that both hurricanes provided, in average, over six regions of local maximum rainfall, including high precipitation efficiencies (72\% for Hugo and 97\% for Isabel), strong low-level flow (24 ms $\mathrm{ms}^{-1}$ for Hugo and $18 \mathrm{~ms}^{-1}$ for Isabel), strong orographically forced upward motion associated with strong low-level flow over relatively gentle upslope with an averaged steepness of $0.03(0.6 \mathrm{~km} / 20 \mathrm{~km})\left(0.72 \mathrm{~m} \mathrm{~s}{ }^{-1}\right.$ for Hugo and $0.54 \mathrm{~m} \mathrm{~s}^{-1}$ for Isabel), concave geometry at several local areas with maximum rainfall (e.g., Regions 1, 5, and 6 for Hugo and Regions 1 and 2 for Isabel) providing a local area of convergence, high moist flow upstream (averaged RH of $86 \%$ for Hugo and $80 \%$ for Isabel), a relatively large convective system associated with both hurricanes (averaged size of $150 \mathrm{~km}$ for both storms), and relatively slower movement of the storms $\left(\sim 6.25 \mathrm{~ms}^{-1}\right.$ for Hugo and $\sim 4.4 \mathrm{~ms}^{-1}$ for Isabel). In short, the key ingredients responsible for producing local heavy orographic rainfall for both storms are: high precipitation efficiency, strong low-level flow, strong orographically forced upward motion associated with strong low-level flow over relatively gentle upslope, concave geometry providing local areas of convergence, high moist flow upstream, a relatively large convective system associated with both hurricanes, and relatively slower 
movement of the storms.

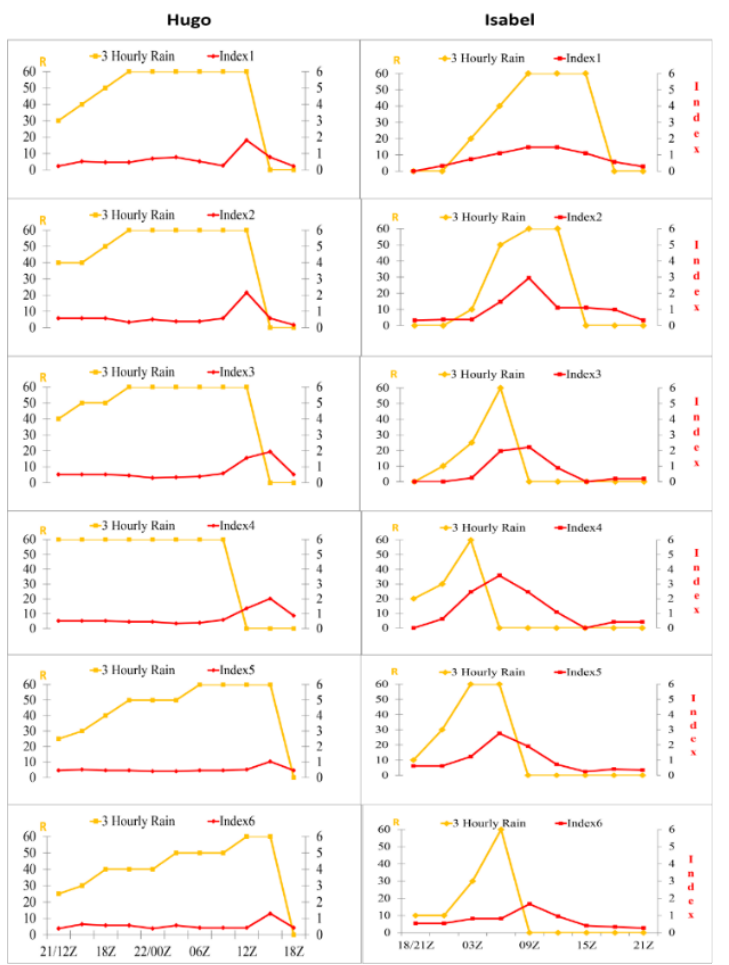

Figure 17. Estimated evolutions of the modified ORI (in red) for Hugo (1989) and Isabel (2003) in Regions 1-6, based on H9 and 19 simulated magnitude $V_{n}$, and $R H$ from both hurricanes versus three hourly rainfall rate $(\mathrm{mm} / 3 \mathrm{~h}, \mathrm{in}$ yellow) for Hugo (right) and Isabel (left). The period is 9/21/12Z - 9/22/18Z for Hugo and 9/18/21Z -

$9 / 19 / 21 \mathrm{Z}$ for Isabel when the TC moves close to the local rainfall maximum region. The symbol "Index $i$ " in the figure panels denotes the ORI for local rainfall maximum region $i$

Based on $\mathrm{H} 1$ and I1 (with 1-km resolution) simulated wind fields, it was found that the estimated orographically induced upward motion $\left(w_{\text {oro }}\right)$ was very close to the total upward motion $\left(w_{\text {total }}\right)$, indicating that the upward motion is dominated by orographic lifting. In addition, we found that the surface- $850 \mathrm{mb}$ averaged CAPE is relatively small $(<$ $500 \mathrm{~J} \mathrm{~kg}^{-1}$ ) for both Hugo and Isabel and there is a lack of negative $\partial \theta_{e} / \partial z$, indicating that there was a lack of conditional and potential instabilities, respectively. Compared to Isabel, Hugo had a slightly higher relative humidity and a stronger low-level flow, but moved much faster and had lower precipitation efficiency, thus produced $25 \%$ less total rainfall. In other words, there was a lack of conditional and potential (convective) instabilities.

The two-dimensional orographic rain index (ORI) proposed in Lin01 was modified to a new form: ORI $=\left(V_{n} \partial h /\right.$ $\partial n)(R H)\left(L_{s} / c_{s}\right)$, where $V_{n}$ is the upstream horizontal wind speed normal to the local mountain range and the key contributor to orographic lifting. The maximum mountain slope $d h / d n$ is estimated at each local location, the storm moving speed $\left(c_{s}\right)$ is estimated by the distance divided by time after landfalling, and $L_{s}$ is approximated by the averaged diameter of the tropical cyclone based on the numerically simulated radar reflectivity. To test this modified ORI, six local regions based on local rainfall maximum were chosen for each hurricane. The evolutions of ORI estimated for each local region was correlated with the rainfall rate for both storms in a general trend. Thus, the modified ORI may serve as a predictor for heavy orographic TC rain.

Before a fine resolution operational forecasting and accurate quantitative precipitation forecast are available, the ORI may still serve as a reliable predictor for heavy orographic TC rain using available observations, numerically simulated flow fields, and local topography data. To avoid rapid variations in time and space, the analyses of several common ingredients, may be made more quantitatively by taking areal and time averaging. Note that the $q_{v}$ in the original formulation of ORI in L01 is substituted by $R H$ in order to avoid normalizing the $q_{v}$. In fact, in the current study we found that both of them work reasonably well. However, due to the sensitivity of RH to temperature, one may consider using $\mathrm{q}_{\mathrm{v}}$, instead of $\mathrm{RH}$. To make the proposed ORI more applicable, it needs to be examined and improved with more cases statistically, such as previously documented cases studies (e.g., Lin et al. 2002, Chiao and Lin 2003, Witcraft et al. 2005, Huang and Lin 2014), as well as with idealized simulations so that the key ingredients can be varied and tested systematically and rigorously. In addition, the inclusion of CAPE and negative $\partial \theta_{e} / \partial z$ should be considered in 
calculating the ORI, especially for non-tropical cyclone heavy orographic rainfall, although they need to be normalized to avoid biasing the index due to potentially large values. This inclusion would allow a broader application of the proposed ORI. To add sensitivity of the mountain geometry to ORI, such as favorable concave region, studies of Jiang (2006) and Watson and Lane (2012) may be considered.

Note that the total accumulated precipitation was underpredicted by the simulated Hurricane Isabel rainfall, which appeared to related to the error caused by the track prediction. It was not as good as the track prediction by the Hugo simulations. Thus, in order to make more accurate orographic rain prediction, it is essential to keep improving track prediction of TCs.

\section{Acknowledgments}

This research was supported by the National Science Foundation Award AGS-1265783. We would like to thank the anonymous reviewers and Drs. L. Liu, A. Mekonnen, Y. Rastigejev, and J. Zhang at the North Carolina A\&T State University for their valuable comments. Michelle Lin's editing on the manuscript is highly appreciated.

\section{References}

Alpert, P. (1986). Mesoscale indexing of the distribution of orographic precipitation over a high mountain. J. Climate. Appl. Meteor., 25, 532-545.

Case, B., \& Mayfield, M. (1990). Atlantic hurricane season of 1989. Mon. Wea. Rev, 118, 1165-1177.

Chen, F., \& Dudhia, J. (2001). Coupling an Advanced Land Surface-Hydrology Model with the Penn State-NCAR MM5 Modeling System. Part I: Model Implementation and Sensitivity. Mon. Wea. Rev., 129, 569-585.

Chiao, S., \& Lin, Y.-L. (2003). Numerical modeling of an orographically enhanced precipitation event associated with Tropical Storm Rachel over Taiwan. Wea Forec., 18, 325-344.

Chien, F.-C., \& Kuo, H.-C. (2011). On the extreme rainfall of Typhoon Morakot (2009). J. Geophys. Res., 116, D05104. http://doi:10.1029/2010JD015092.

Doswell, C. A. III, Brooks, H., \& Maddox, R. (1996). Flash flood forecasting: An ingredient-based methodology. Wea Forec., 11, 560-581.

Doswell, C. A. III, Ramis, C., Romero, R., \& Alonso, S. (1998). A diagnostic study of three heavy precipitation episodes in the western Mediterranean region. Wea. Forec., 13, 102-124.

Harville, S. L. (2009). (H09) Effects of Appalachian topography on precipitation from landfalling hurricanes. MS thesis. North Carolina State Univ. http://repository.lib.ncsu.edu/ir/handle/1840.16/2849.

Hollifield, J., \& Lackey, S. C. (1989). Storm Data and Unusual Weather Phenomena: September 1989. National Climatic Data Center (Report). Asheville, North Carolina, NOAA, pp. 46-49.

Hong, C. C., Lee, M. Y., Hsu, H. H., \& Kuo, J. L. (2010). Role of submonthly disturbance and 40-50 day ISO on the extreme rainfall event associated with Typhoon Morakot (2009) in Southern Taiwan. Geophys. Res. Lett., 37, L08805. http://doi:10.1029/2010GL042761, 2010.

Hong, S.-Y., Noh, Y., \& Dudhia, J. (2006). A new vertical diffusion package with an explicit treatment of entrainment processes. Mon. Wea. Rev., 134, 2318-2341.

Houze, R. A. Jr. (2012). Orographic effects on precipitating clouds. Rev. Geophys., 50, RG1001. http://doi:10.1029/2011RG000365.

Huang, Y.-C., \& Lin, Y.-L. (2014). A Study on the Structure and Precipitation of Typhoon Morakot (2009) Induced by the Central Mountain Range of Taiwan. Mon. Wea. Rev., 123, 115-141.

Jiménez, P. A., Dudhia, J., González-Rouco, J. F., Navarro, J., Montávez, J. P., \& García-Bustamante, E. (2012). A revised scheme for the WRF surface layer formulation. Mon. Wea. Rev., 140, 898-918.

Jiang, Q. (2006). Precipitation over concave terrain. J. Atmos. Sci., 63, 2269-2288.

Kain, J. S. (2004). The Kain-Fritsch convective parameterization: An update. J. Applied Meteor., 43, 170-181. https://doi.org/10.1175/1520-0450(2004)043\%3C0170:TKCPAU\%3E2.0.CO;2

Lawrence, M. B., Avila, L. A., Beven, II, J. L., Franklin, J. L., Pasch, R. J., \& Stewart, S. R. (2005). Atlantic hurricane season of 2003. Mon. Wea. Rev., 133, 1744-1773.

LDAS (2015). North America Land Data Assimilation System (NLDAS). Land Data Assimilation System, NASA, Retrieved from https://ldas.gsfc.nasa.gov/nldas.

Lin, C.-Y., Hsu, H.-M., Sheng, Y.-F., Kuo, C.-H., \& Liou, Y.-A. (2011). Mesoscale processes for super heavy rainfall of 
Typhoon Morakot (2009) over southern Taiwan. Atmos. Chem. Phys., 11, 345-361.

Lin, N., Smith, J. A., Villarini, G., Marchok, T. P., \& Baeck, M. L. (2010). Modeling extreme rainfall, winds, and surge from hurricane Isabel (2003). Wea. Forec., 25, 1342-61.

Lin, Y.-L. (2007). Mesoscale Dynamics. Cambridge, England: Cambridge University Press.

Lin, Y.-L., Chen, S.-H., \& Liu, L. (2016). Orographic effects on track deflection of an idealized tropical cyclone passing over a mesoscale mountain range. J. Atmos. Sci., 73, 3951-3974.

Lin, Y.-L., Ensley, D. B., Chiao, S., \& Huang, C.-Y. (2002). Orographic Influences on Rainfall and Track Deflection Associated with the Passage of a Tropical Cyclone. Mon. Wea. Rev., 130, 2929-2950.

Lin, Y.-L., Chen, S.-Y., Hill, C. M., \& Huang, C.-Y. (2005). Control parameters for the influence of a mesoscale mountain range on cyclone track continuity and deflection. J. Atmos. Sci., 62, 1849-1866.

Lin, Y.-L., Chiao, S., Thurman, J. A., Wang, T.-A. Kaplan, M. L., \& Weglarz, R. P. (2001). (Lin01) Some common ingredients for heavy orographic rainfall and their potential application for prediction. Wea. Forec., 16, 633-660.

Liu, L., Lin, Y.-L., \& Chen, S.-H. (2016). Effects of landfall location and approach angle of an idealized tropical cyclone over a long mountain range. Frontiers in Earth Sci, 4, 14. http://doi.org/10.3389/feart.2016.00014.

Mielikainen, J., Huang, B., Huang, A., \& Goldberg, M. (2012). GPU Acceleration of the Updated Goddard Shortwave Radiation Scheme in the Weather Research and Forecasting (WRF) Model. IEEE J. Selec. Topics Appl. Earth Obs. Remote Sensing, 5(2), 555-562.

Mlawer, E. J., Taubman, S. J., Brown, P. D., Iacono, M. J., \& Clough, S. A. (1997). Radiative transfer for inhomogeneous atmospheres: RRTM, a validated correlated-k model for the longwave. J. Geophys. Res. Atmos., $102,16663-16682$.

NHC (2016). NHC Official Intensity Error trend - Atlantic Basin tropical cyclones. National Hurricane Center, National Wea. Service, NOAA. Retrieved from http://www.nhc.noaa.gov/verification/verify5.shtml.

Nolan, D. S., Zhang, J. A., \& Stern, D. P. (2009). Evaluation of planetary boundary layer parameterizations in tropical cyclones by comparison of in situ observations and high-resolution simulations of Hurricane Isabel (2003). Part I: Initialization, maximum winds, and the outer-core boundary layer. Mon. Wea. Rev., 137, 3651-3674.

Powell, M. D., Dodge, P. P., \& Black, L. B. (1991). The landfall of Hurricane Hugo in the Carolinas: Surface wind distribution. Wea. Forec., 6, 379-399.

Rostom, R., \& Lin, Y.-L. (2015). Control Parameters for Track Continuity of Cyclones Passing over the South-Central Appalachian Mountains. Wea. Forec., 30, 1429-1449.

Roth, D. (2005). Rainfall Summary for Hurricane Isabel. Hydrometeor. Pred. Center., NOAA. Retrieved from http://www.wpc.ncep.noaa.gov/tropical/rain/isabel2003.html.

Schwarz, F. K. (1970). The unprecedented rains in Virginia associated with the remnants of Hurricane Camille. Mon. Wea. Rev., 98, 851-859.

Skamarock, W. C., Klemp, J. B., Dudhia, J., Gill, D. O., Barker, D. M., Duda, M. G., Huang, X.-Y., Wang, W., \& Powers, J. G. (2008). A description of the Advanced Research WRF version 3. NCAR Technical note-475+ STR, 113 pp. http://www.mmm.ucar.edu/wrf/users/docs/arw_v3.pdf.

Smith, R. B. (1979). The influence of mountains on the atmosphere. In B. Saltzman (Ed.), Advances in Geophysics (Vol. 21, pp. 87-230). New York, NY: Academic Press.

Stewart, S. (2005). Hurricane Ivan 2 - 24 September 2004. Tropical Cyclone Report, National Hurricane Center, 27 May 2005. Retrieved from http://www.nhc.noaa.gov/2004ivan.shtml.

Thompson, G., Paul, M. R., Roy, M. R., \& William, D. H. (2008). Explicit forecasts of winter precipitation using an improved bulk microphysics scheme. Part II: implementation of a new snow parametrization. Mon. Wea. Rev., 136, 5095-5115.

Watson, C. D., \& Lane, T. P. (2012). Sensitivities of orographic precipitation to terrain geometry and upstream conditions in idealized simulations. J. Atmos. Sci., 69, 1208-1231.

Witcraft, N. C., Lin, Y.-L., \& Kuo, Y.-H. (2005). Dynamics of orographic rain associated with the passage of a tropical cyclone over a mesoscale mountain. Terr. Atmos. Ocean, 16, 1133-1161.

WPC (2016). Quantitative Precipitation Forecasts. Wea Pred Center, National Wea. Service, NOAA. Retrieved from http://www.wpc.ncep.noaa.gov/qpf/qpf2.shtml. 
Wu, C.-C., Yen, T.-H., Kuo, Y.-H., \& Wang, W. (2002). Rainfall accumulation associated with Typhoon Herb (1996) near Taiwan. Part I: The topographic effect. Wea. Forec., 17, 1001-1015.

Wu, L., Liang, J., \& Wu, C.-C. (2011). Monsoonal Influence on Typhoon Morakot (2009). Part I: Observational Analysis. J. Atmos. Sci., 68, 2208-2221.

Yen, T.-H., Wu, C.-C., \& Lien, G.-Y. (2011). Rainfall simulations of Typhoon Morakot with controlled translation speed based on EnKF data assimilation. Terr. Atmos. Ocean, 22, 647-660.

Zhao, Q., \& Jin, Y. (2008). High-resolution radar data assimilation for Hurricane Isabel (2003) at landfall. Bull. Amer. Meteor. Soc., 89, 1355-1372.

\section{Copyrights}

Copyright for this article is retained by the author(s), with first publication rights granted to the journal.

This is an open-access article distributed under the terms and conditions of the Creative Commons Attribution license (http://creativecommons.org/licenses/by/4.0/). 